\title{
Coupling endoplasmic reticulum stress to the cell- death program: a novel HSP90-independent role for the small chaperone protein p23
}

\author{
RV Rao ${ }^{\star, 1}, K_{\text {Niazi }}{ }^{1}, \mathrm{P}$ Mollahan ${ }^{1}, \mathrm{X} \mathrm{Mao}^{1}$, D Crippen ${ }^{1}$, \\ KS Poksay ${ }^{1}$, S Chen ${ }^{1}$ and DE Bredesen*,1,2 \\ 1 The Buck Institute for Age Research, 8001 Redwood Blvd., Novato, CA 94945 \\ USA \\ 2 Department of Neurology, University of California, San Francisco, CA 94143, \\ USA \\ * Corresponding authors: RV Rao and DE Bredesen, The Buck Institute for Age \\ Research, 8001 Redwood Blvd., Novato, CA 94945, USA \\ Tel: + 1415209 2000; Fax: + 1415209 2230; \\ E-mail: rrao@buckinstitute.org
}

Received 24.5.05; revised 20.7.05; accepted 22.7.05; published online 30.9.05 Edited by P Mehlen

\section{Abstract}

The endoplasmic reticulum (ER) is the principal organelle for the biosynthesis of proteins, steroids and many lipids, and is highly sensitive to alterations in its environment. Perturbation of $\mathrm{Ca}^{2+}$ homeostasis, elevated secretory protein synthesis, deprivation of glucose or other sugars, altered glycosylation and/or the accumulation of misfolded proteins may all result in ER stress, and prolonged ER stress triggers cell death. Studies from multiple laboratories have identified the roles of several ER stress-induced cell-death modulators and effectors through the use of biochemical, pharmacological and genetic tools. In the present work, we describe the role of p23, a small chaperone protein, in preventing ER stress-induced cell death. p23 is a highly conserved chaperone protein that modulates HSP90 activity and is also a component of the steroid receptors. p23 is cleaved during ER stress-induced cell death; this cleavage, which occurs close to the carboxy-terminus, requires caspase-3 and/or caspase-7, but not caspase-8. Blockage of the caspase cleavage site of p23 was associated with decreased cell death induced by ER stress. Immunodepletion of p23 or inhibition of p23 expression by siRNA resulted in enhancement of ER stress-induced cell death. While p23 co-immunoprecipitated with the BH3-only protein PUMA (p53-upregulated modulator of apoptosis) in untreated cells, prolonged ER stress disrupted this interaction. The results define a protective role for $\mathrm{p} 23$, and provide further support for a model in which ER stress is coupled to the mitochondrial intrinsic apoptotic pathway through the activities of $\mathrm{BH} 3$ family proteins.

Cell Death and Differentiation (2006) 13, 415-425.

doi:10.1038/sj.cdd.4401761; published online 30 September 2005

Keywords: endoplasmic reticulum; ER stress; p23; HSP90; caspase; apoptosis
Abbreviations: ER, endoplasmic reticulum; pcd, programmed cell death; RNAi, RNA interference

\section{Introduction}

An imbalance between the load of newly synthesized proteins in the endoplasmic reticulum (ER) and the organelle's proteinfolding capacity triggers ER stress. ER stress may also result from alterations in $\mathrm{Ca}^{2+}$ homeostasis, viral infections, hypoxia, ischemia, mutations that impair client protein folding and accumulation of misfolded proteins (either within or outside the ER itself). ${ }^{1,2}$ Prolonged ER stress impairs the protective mechanisms designed to promote correct folding and degrade faulty proteins, ultimately leading to organelle dysfunction and programmed cell death (pcd). ${ }^{2-5}$ Studies from multiple laboratories have disclosed roles for several ER stress-induced cell-death modulators and effectors. ${ }^{6}$ There is a growing realization that some such mediators may be specific for a given inducer or set of inducers. ${ }^{7}$

In our earlier study, we used a set of complementary approaches including two-dimensional gel electrophoresis coupled with MALDI-TOF mass spectrometry and nano-LCESI-MS/MS (matrix-assisted laser desorption ionization-time of flight mass spectrometry and nano-liquid chromatographyelectrospray ionization mass spectrometry with tandem mass spectrometry), RNA interference (RNAi), co-immunoprecipitation, immunodepletion of candidate proteins, and reconstitution studies, and identified the calcium-binding protein apoptosis-linked gene-2 (ALG-2), and valosin-containing protein (VCP), as mediators of ER stress-induced pcd. ${ }^{7}$ In the present report we describe the role of $\mathrm{p} 23$, a small chaperone protein, in preventing ER stress-induced cell death. Specifically, p23 seems to function as an antiapoptotic protein by interacting with the $\mathrm{BH} 3$-only proapoptotic protein PUMA, and to exert a protective effect that is abrogated following ER stress-induced caspase-dependent cleavage near its carboxy-terminus, associated with the release of PUMA and the availability of PUMA to interact with Bax.

\section{Results}

\section{Evaluation of HSP90 and p23 in ER stress-induced cell death}

We previously generated a list of 40 candidate ER-apoptosomal mediators of ER stress-induced apoptosis, ${ }^{7}$ and described in detail the roles of apoptosis-linked gene-2 (ALG-2) and VCP in mediating ER stress-induced pcd. ${ }^{7}$ As part of our continuing investigation of these candidates, we assessed the role of HSP90, which showed at least a 1.5-fold increase in ER-stressed HEK 293T cells, as determined by two-dimensional IEF/SDS-PAGE patterns (data not shown). Further analysis of cell-free cytosolic extracts revealed different 


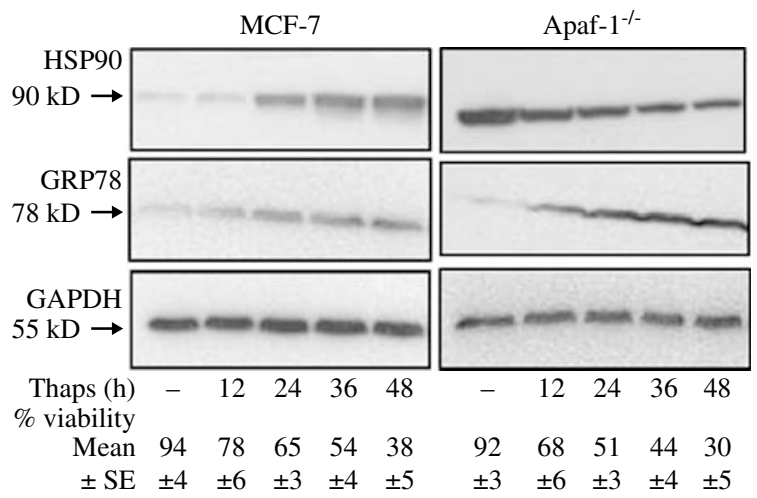

Figure 1 HSP90 protein expression during ER stress. HSP90 protein expression in MCF-7 cells and Apaf- $1^{-1-}$ fibroblasts treated with 2.0 and $0.5 \mu \mathrm{M}$ thapsigargin, respectively, for different time periods. Cell extracts $(150 \mu \mathrm{g}$ protein) were then analyzed by Western blot analysis for HSP90 expression. Increased levels of GRP78 protein expression in similar extracts indicate ER stress response. Surviving versus apoptotic cells were quantified as described in the Materials and Methods. Data (mean \pm S.E.) are from more than three independent experiments. Each figure is representative of at least three independent experiments

HSP90 protein expression patterns in different cell lines: while cell extracts from MCF-7 or 293T cells treated with thapsigargin showed increased HSP90 expression, Apaf- $1^{-1-}$ cells showed decreased HSP90 expression with time of thapsigargin treatment (Figure 1). Similar HSP90 expression profiles were also observed in cells undergoing ER stress triggered by brefeldin-A (data not shown). Evidence of ER stress was the high level of GRP78 protein expression ${ }^{2,3,8}$ following thapsigargin treatment of both Apaf- $1^{-1-}$ and MCF-7 cells (Figure 1). Since HSP90 protein expression was not induced consistently in different cell types following ER stress, we turned our attention to p23, an HSP90-associated chaperone protein. p23 is a widely expressed protein, and a subpopulation of p23 exists in complex with HSP90. The p23-HSP90 protein complex is involved in the assembly of steroid hormone receptor and telomerase complexes, and also regulates the binding, folding and processing of proteins. ${ }^{9,10}$

We assessed the expression of p23 in cell extracts isolated from untreated and ER stress-induced cells. As shown in Figure 2, p23 is a low molecular weight $(23 \mathrm{kD})$ chaperone protein whose expression is detectable both in MCF-7 and Apaf- $1^{-1-}$ fibroblasts. Treatment with ER stress-inducing agents resulted in the cleavage of p23 to a species of lower molecular mass (approximately $19 \mathrm{kD}$ ) in both cell types (Figure 2a). (It should be noted that MCF-7 cells have been shown not to mount an ER stress response when exposed to tunicamycin treatment, ${ }^{11}$ and this may explain the lack of cleavage of p23 in tunicamycin-treated MCF-7 cells (Figure 2a)). Processing of p23 to the $19 \mathrm{kD}$ band was also seen in primary neuronal cells exposed to hypoxia (data not shown). This was also associated with a high level of GRP78 protein expression in cells, indicative of hypoxia-induced ER stress (data not shown).

Based on our earlier studies on the involvement of various caspases in ER stress-induced cell death, we proceeded to determine whether or not p23 cleavage was accompanied by a

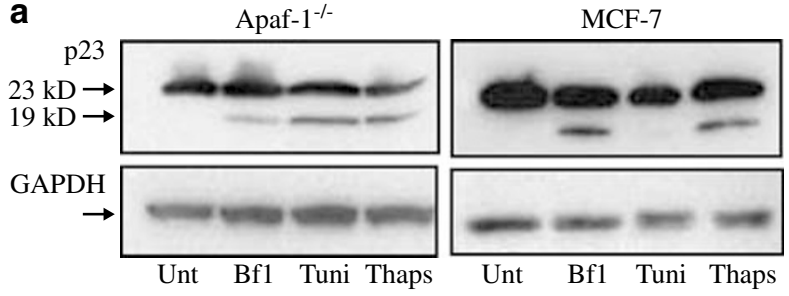

b

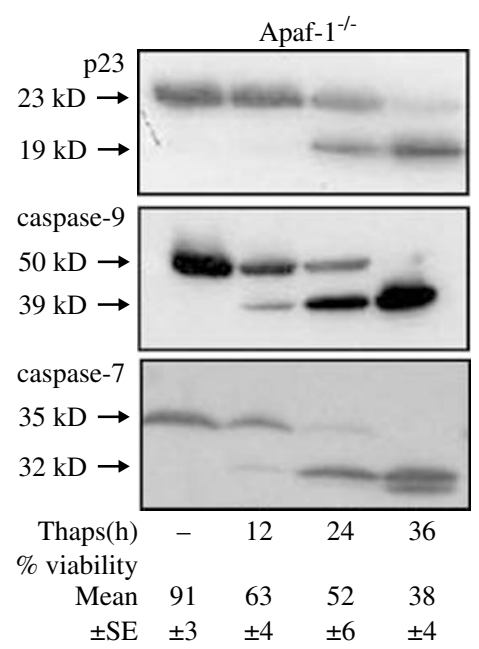

Figure 2 p23 protein expression during ER stress. p23 protein expression in Apaf- $1^{-1-}$ fibroblasts and MCF-7 cells treated with various ER stress inducers for $24 \mathrm{~h}$. (a) Apaf- $1^{-1-}$ fibroblasts were treated with $1.0 \mu \mathrm{M}$ brefeldin-A, $2.0 \mu \mathrm{g} / \mathrm{m}$ tunicamycin, and $0.5 \mu \mathrm{M}$ thapsigargin. MCF-7 cells were treated with $2.0 \mu \mathrm{M}$ brefeldin- $\mathrm{A}, 2.0 \mu \mathrm{g} / \mathrm{ml}$ tunicamycin, and $2.0 \mu \mathrm{M}$ thapsigargin. Cell extracts ( $150 \mu \mathrm{g}$ protein) were then analyzed by Western blot analysis for p23 expression. MCF-7 cells do not elicit an ER stress response when cells are exposed to tunicamycin treatment. Cell extracts were also probed with GAPDH as a loading control. (b) p23 cleavage is accompanied by caspase processing. Cell extracts ( $150 \mu \mathrm{g}$ of protein) were prepared from cells treated with $0.5 \mu \mathrm{M}$ thapsigargin for various time periods. p23 is cleaved to a low Mw species (approximately $19 \mathrm{kD}$ ) and thapsigargin-induced p23 cleavage is also accompanied by caspase- 9 and -7 processing. Surviving versus apoptotic cells were quantified as described in Materials and Methods. Data are from three independent experiments

caspase processing. As shown in Figure $2 b$, thapsigargininduced p23 cleavage was accompanied by caspase- 9 and -7 processing. The anti-caspase- 9 antibody recognized the fulllength $50 \mathrm{kD}$ band and the amino-terminal-cleaved product (39 kD, prodomain + large subunit) of caspase- $9 .{ }^{12}$ As shown in Figure $2 \mathrm{~b}$, complete processing of the proform to the $39 \mathrm{kD}$ product occurred by $36 \mathrm{~h}$ of treatment. Similarily, we assessed the expression of caspase-7, a caspase activated by ER stress. $^{12,13}$ Procaspase-7 (35 kD) is first converted to a $32 \mathrm{kD}$ intermediate (prodomain + large subunit), which is further processed into active subunits consisting of 20 and $11 \mathrm{kD}$ forms. ${ }^{12}$ Similarly, ER stress-induced cell death was accompanied by processing of caspases-12 and -3 in Apaf- $1^{-/-}$ fibroblasts and caspase-7 in MCF-7 cells (data not shown).

\section{Mutation of caspase cleavage site prevents processing of p23}

We next sought to determine whether ER stress-induced cleavage of p23 is a caspase-dependent phenomenon. As 
shown in Figure $3 a$, while the addition of purified active caspase-8 to cell extracts failed to cleave p23, addition of purified active caspase- 3 or -7 resulted in the cleavage of p23 protein and appearance of a $19 \mathrm{kD}$ band. The p23 cleaved fragments arising from thapsigargin and brefeldin-A treatment closely matched the fragment sizes generated from caspase3 and -7 cleavage of p23. Appearance of the proteolytic fragment of $\mathrm{p} 23$ triggered by brefeldin-A treatment was also blocked by the pan caspase inhibitor zVAD-fmk (Figure 3b), suggesting that caspases are likely to cleave p23.

The antibody used to detect p23 was raised against the $\mathrm{N}$-terminal 94 amino-acid residues of mouse p23 protein. Since the antibody was capable of detecting the $19 \mathrm{kD}$ cleaved fragment of p23, it suggested that the p23 cleavage site occurred at the carboxy-terminus. The C-terminal sequence of p23 contains eight potential caspase cleavage sites (Figure $3 \mathrm{c}$ ). We therefore generated several single, double and triple mutants of p23. The mutant proteins were expressed in 293T cells. Cellular extracts were incubated with recombinant purified caspase-3 or -7 . As shown in
Figure 3d, except for D142N, none of the other mutations (D145N, D150N, D153N, D150/153N or D145/150/153N) blocked cleavage of $\mathrm{p} 23$ by caspases-3 and -7. A single mutation at D142, however, prevented the protein from being cleaved by recombinant caspases.

We next determined whether or not ER stress-mediated cell death is blocked by p23 caspase mutants. MCF-7 cells were either transfected with a mock vector, WT p23, p23D142N or p23D150/153N mutant constructs. At 24 $\mathrm{h}$ after transfection, thapsigargin $(2 \mu \mathrm{M})$ or brefeldin- $\mathrm{A}(2 \mu \mathrm{M})$ was added to cells. Cell viability was measured $24 \mathrm{~h}$ after treatment, as described earlier. $^{8,12}$ While WTp23 suppressed to some extent ER stress induced by brefeldin-A or thapsigargin, the expression of p23D142N mutant significantly suppressed cell death induced by both agents. Both the mock vector and the p23D150/153N mutant construct failed to block cell-death induction by thapsigargin or brefeldin-A. Similarly, expression of the p23D142N mutant also suppressed cell death induced by non-ER stress agents including etoposide ( $25 \mu \mathrm{M}$; data not shown). This suggested that p23D142 is a critical site that is a

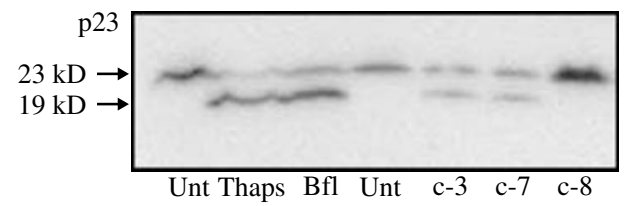

b

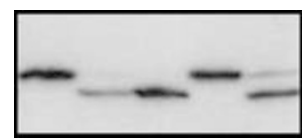

ZVAD

c

D L P E V D G A D D D S Q D S D D E K M P D L E

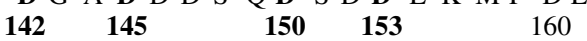

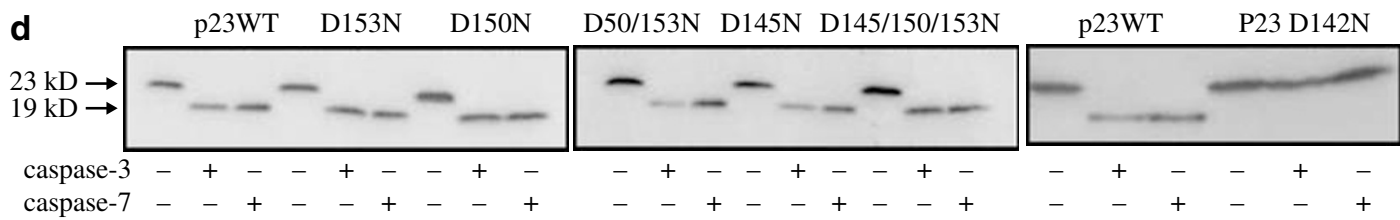

WB: FLAG

e

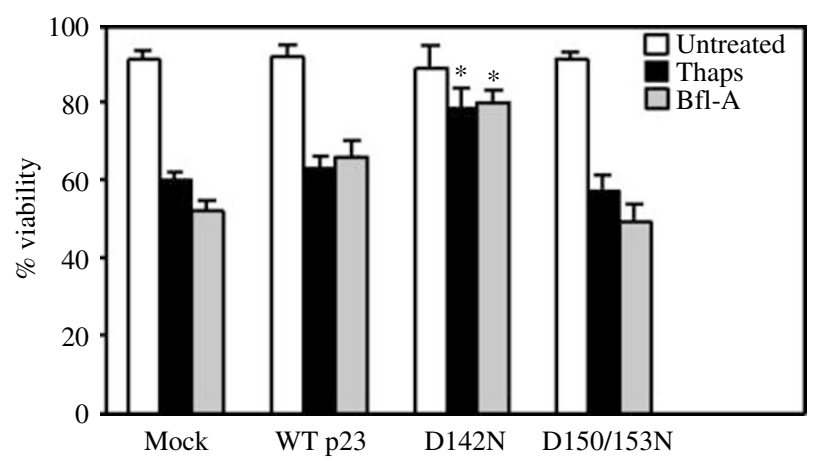

Figure 3 ER stress-induced cleavage of p23 is a caspase-dependent phenomenon. (a and $\mathbf{b}$ ) p23 protein expression in Apaf-1 $1^{-1-}$ fibroblasts treated with $0.5 \mu \mathrm{M}$ thapsigargin or $1.0 \mu \mathrm{M}$ brefeldin-A in the presence or absence of ZVAD-fmk. Purified active caspase-3 $(50 \mathrm{ng} / \mathrm{ml})$, caspase-7 (100 ng/ml) or caspase-8 (1.0 $\mu \mathrm{g} / \mathrm{ml})$ was added to cell-free cytosolic extracts ( $150 \mu \mathrm{g}$ protein) made from Apaf- $1^{-1-}$ fibroblasts (lanes 5-7). Extracts were incubated at $37^{\circ} \mathrm{C}$ for $1 \mathrm{~h}$, separated on SDS-PAGE gels, transferred to PVDF membrane and incubated with p23 antibody. p23 is cleaved to a low Mw (19 kD) species (a) that is blocked by ZVAD-fmk (b). (c) Potential caspase cleavage sites in p23. A total of eight ' $D$ ' (aspartate) residues exist in the carboxy-terminus that are potential sites for caspase activity. (d) p23 has several potential caspase sites at the carboxy-terminus. Site-directed mutagenesis of several of these sites were carried out as described in Materials and Methods. Cell-free extracts were made from 293T cells transfected with wild-type Flagp23, D142N, D145N, D150N, D153N, D150/153N and D145/150/153N constructs. Samples (150 $\mu \mathrm{g}$ protein) were incubated with $50 \mathrm{ng} / \mathrm{ml}$ caspase-3 or $100 \mathrm{ng} / \mathrm{ml}$ caspase- 7 at $37^{\circ} \mathrm{C}$ for $1 \mathrm{~h}$. Samples were analyzed by immunoblotting with anti-FLAG antibody to detect p23 and its cleavage product $(19 \mathrm{kD})$. (e) p23 caspase mutant inhibits ER stress-induced cell death. MCF-7 cells were transfected with $6 \mu \mathrm{g}$ of pcDNA3, pcDNAp23, p23D142N or p23D150/153N mutant constructs. After $24 \mathrm{~h}$, cells were treated with $2.0 \mu \mathrm{M}$ thapsigargin (Thaps) or $2.0 \mu \mathrm{M}$ brefeldin-A (Bfl-A) for $24 \mathrm{~h}$. Cells were gently lifted and washed once with PBS at room temperature. Surviving versus apoptotic cells were quantified as described in the Materials and Methods. ${ }^{*} P<0.05$ 
susceptible to caspase cleavage, and cleavage at this site may lead to a loss of the antiapoptotic function of p23, both in ER stress and non-ER stress insults.

\section{Subcellular localization of p23}

p23 is a widely expressed chaperone protein that is involved in the binding, folding and processing of proteins, as well as the assembly of steroid hormone receptor and telomerase complexes (these events are closely associated with the ER) ${ }^{9,10}$ While caspase-3 is predominantly cytosolic, we and others have shown that caspase-7 is associated with ER during ER stress. ${ }^{8,13}$ Since ER stress-induced cell death results in caspase-7- and casapse-3-mediated cleavage of p23, it prompted us to examine the subcellular localization of p23.

To determine the localization of p23, we performed immunocytochemistry on untreated and hypoxic cortical neuronal cells using antibodies specific to p23 and calreticulin. The antibody to p23 stained within the cytosolic compartment with a granular pattern in the perinuclear region (Figure 4a, green). Calreticulin, a marker protein for $E R$, demonstrated robust, punctate staining predominantly in the ER (Figure 4a, red). Approximately half the green fluorescent volume (p23) in the untreated sample was found to colocalize with the calretriculin channel, with no change in the overall fraction of colocalization following 24 or $48 \mathrm{~h}$ of hypoxia.

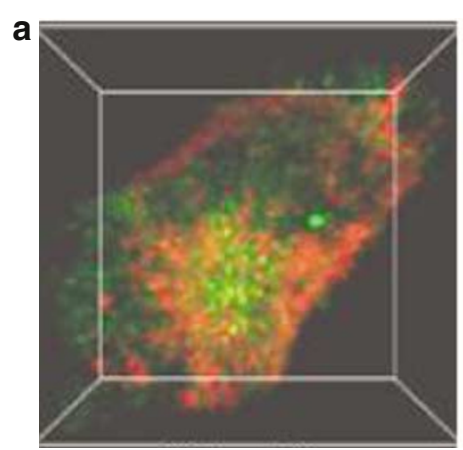

Untreated

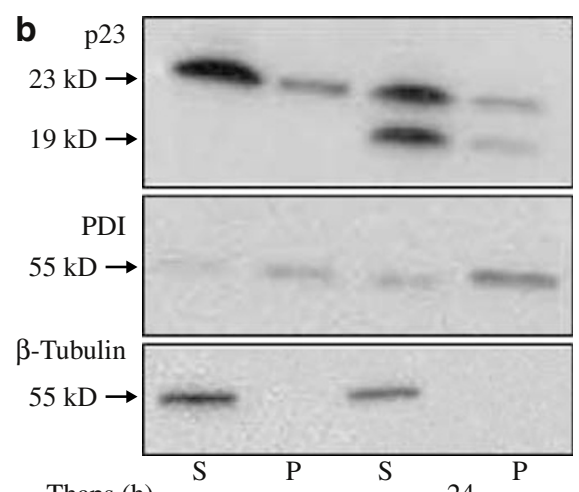

Thaps (h)

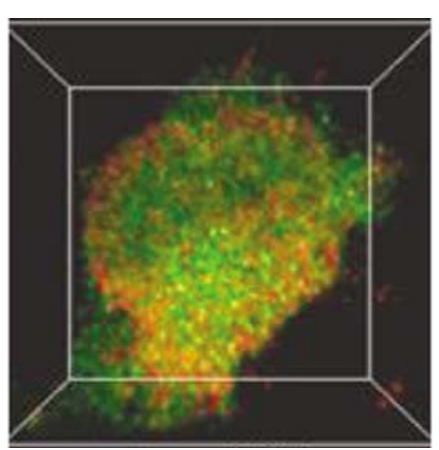

Hypoxia, 24h

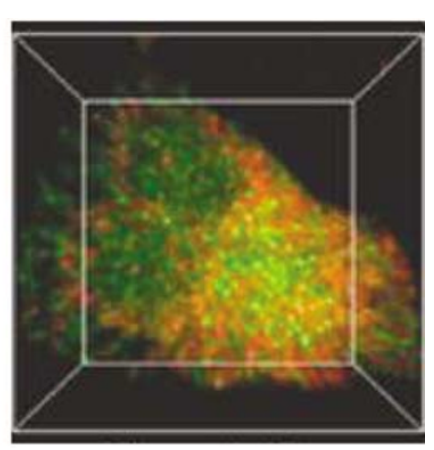

Hypoxia, 48h
C

$$
\begin{aligned}
& \text { 400,000g extract } \\
& 400,000 \mathrm{~g} \text { extract (-p23) } \\
& \text { microsomes } \\
& \text { (untreated) } \\
& \text { microsomes (from } \\
& \text { Thaps treated cells) } \\
& \text { microsomes (from Thaps } \\
& \text { treated cells, -p23) }
\end{aligned}
$$

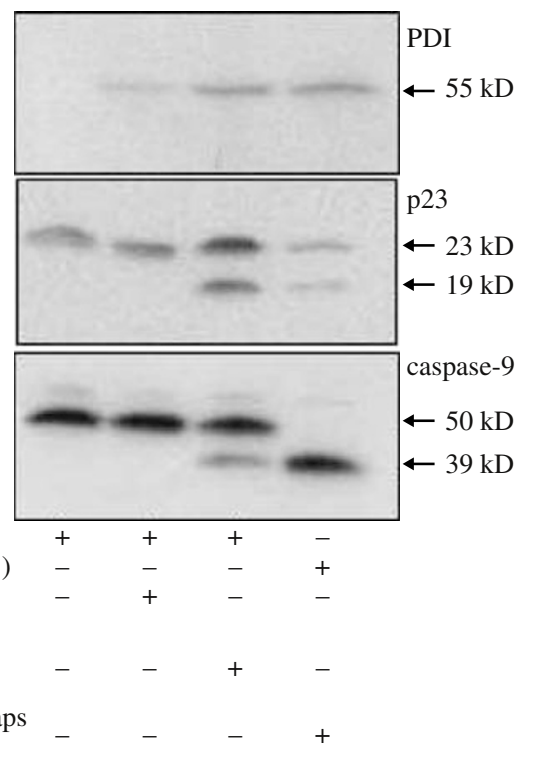

Figure 4 Subcellular localization of p23. (a) Immunofluorescent staining for p23 before and after subjecting cortical neurons to hypoxia. For the detection of p23, cells were stained with anti-p23 monoclonal antibody as the primary antibody and 488-conjugated donkey anti-mouse lgG as the secondary antibody (green). Cells were also stained with anti-calreticulin polyclonal antibody and 555-conjugated donkey anti-rabbit lgG (red) as the secondary antibody. (b) Microsomes were isolated from cell-free extracts prepared from untreated or thapsigargin-treated Apaf-1 $1^{-1-}$ fibroblasts $(24 \mathrm{~h})$ as described in Materials and Methods. A total of $50 \mu \mathrm{g}$ of protein from the $400000 \times g$ supernatant (S) and microsomal (P) fractions was subjected to SDS-PAGE and Western blotting. Membranes were probed with anti-p23 monoclonal antibody. Cellular fractions were also probed with anti-PDI (protein disulfide isomerase) antibody and anti- $\beta$-tubulin as standard marker proteins for ER and cytosol, respectively. (c) p23 is required for the processing of caspase-9 in response to thapsigargin-induced ER stress. Untreated cell extracts and microsomes isolated from $24 \mathrm{~h}$ thapsigargin-treated cell extract were immunodepleted of p23 using the p23 monoclonal antibody. Samples were spun briefly to pellet the protein A/G-Sepharose conjugate. The supernatant was collected, subjected to SDS-PAGE, and probed for (1) p23 that would indicate the extent of immunodepletion and (2) PDI as ER marker protein to serve as loading controls. Additionally, a caspase-9 processing assay was carried out by incubating $100 \mu \mathrm{g}$ of the supernatant protein at $37^{\circ} \mathrm{C}$ for $1 \mathrm{~h}$ with untreated cell extracts or extracts that had been immunodepleted of p23. Following the reactions, samples were analyzed by SDS-PAGE and Western blotting. Membranes were probed with anticaspase- 9 antibody. Note that the reduction of p23 was approximately $75 \%$ 
p23 localization was also determined in cellular extracts isolated from cells before and/or after ER stress. Apaf-1 $1^{-/-}$ fibroblasts were either left untreated or treated with $0.5 \mu \mathrm{M}$ thapsigargin. Cell-free cytosolic extracts that lack whole cells, nuclei, and mitochondria were recentrifuged at $400000 \times g$ for $1 \mathrm{~h}$ for the preparation of microsomes, as described under Materials and Methods. Microsomes $(400000 \times g$ pellet $(P))$ and the $400000 \times g$ supernatant (S) were both subjected to SDS-PAGE and Western blot analysis. As shown in Figure 4b, p23 was predominantly present in the supernatant fractions, with a lower expression in the microsomal fractions. Treatment with thapsigargin resulted in the appearance of the $19 \mathrm{kD}$ cleaved band. There was a decreased expression of both the 23 and $19 \mathrm{kD}$ bands in the microsomal fraction isolated from thapsigargin-treated cells. A similar pattern of expression was also seen in cellular extracts isolated from MCF-7 cells treated with $2.5 \mu \mathrm{M}$ brefeldin (data not shown). While the data indicate that p23 is predominantly a cytosolic protein with a subpopulation of p23 also associated with the ER compartment, comparison of the immunochemical staining with the fractionation studies indicates that localization of p23 may also depend on the cell type.

To determine whether $\mathrm{p} 23$ was required for the processing of caspases, we immunodepleted p23 from untreated cell extracts and fragmented (sonicated) microsomes isolated from thapsigargin-treated Apaf- $1^{-1-}$ cells as described earlier. ${ }^{7,12}$ Since there was a greater population of p23 in the supernatant fraction, it was decided to immunodeplete both the microsomal and supernatant fractions. Immunodepletion resulted in a decrease of p23 protein by approximately 70$80 \%$. The immunodepleted microsomal fraction was incubated with immunodepleted cytosolic extracts and the effects compared to those extracts that had not been immunodepleted. As shown in Figure 4c, immunodepletion of p23 enhanced the degree of cleavage of procaspase-9 (lane 4). While the results do not reveal the specific contribution of microsomal versus cytosolic p23 to caspase processing, the data do suggest that p23 (alone and/or in combination with other molecule(s)) may play a role in blocking ER stressinduced caspase activation (at least in this model system).

\section{Effect of RNAi on ER stress-induced caspase activation and cell death}

To complement the results obtained from immunodepletion studies and to evaluate the effects of reducing p23 concentration in cells (as opposed to extracts), we used RNAi to reduce the expression of p23. Small interfering RNAs (siRNAs) were designed to target two regions of the p23 gene, based on predicted accessible (loop) and unique (specific) regions. As shown in Figure 5a, siRNA-targeting nucleotides 419-429 and 446-466 were very effective in reducing the expression of p23 protein (by approximately 50 and $70 \%$, respectively). A combination of these two siRNAs nearly eliminated the expression of p23 (approximately 90\% reduction, Figure $5 \mathrm{a}, \mathrm{comb})$. The siRNAs did not affect the expression of HSP90.

The effect of RNAi on ER stress-induced caspase activation and cell death was studied by treating Apaf-1 $1^{-1-}$ cells with
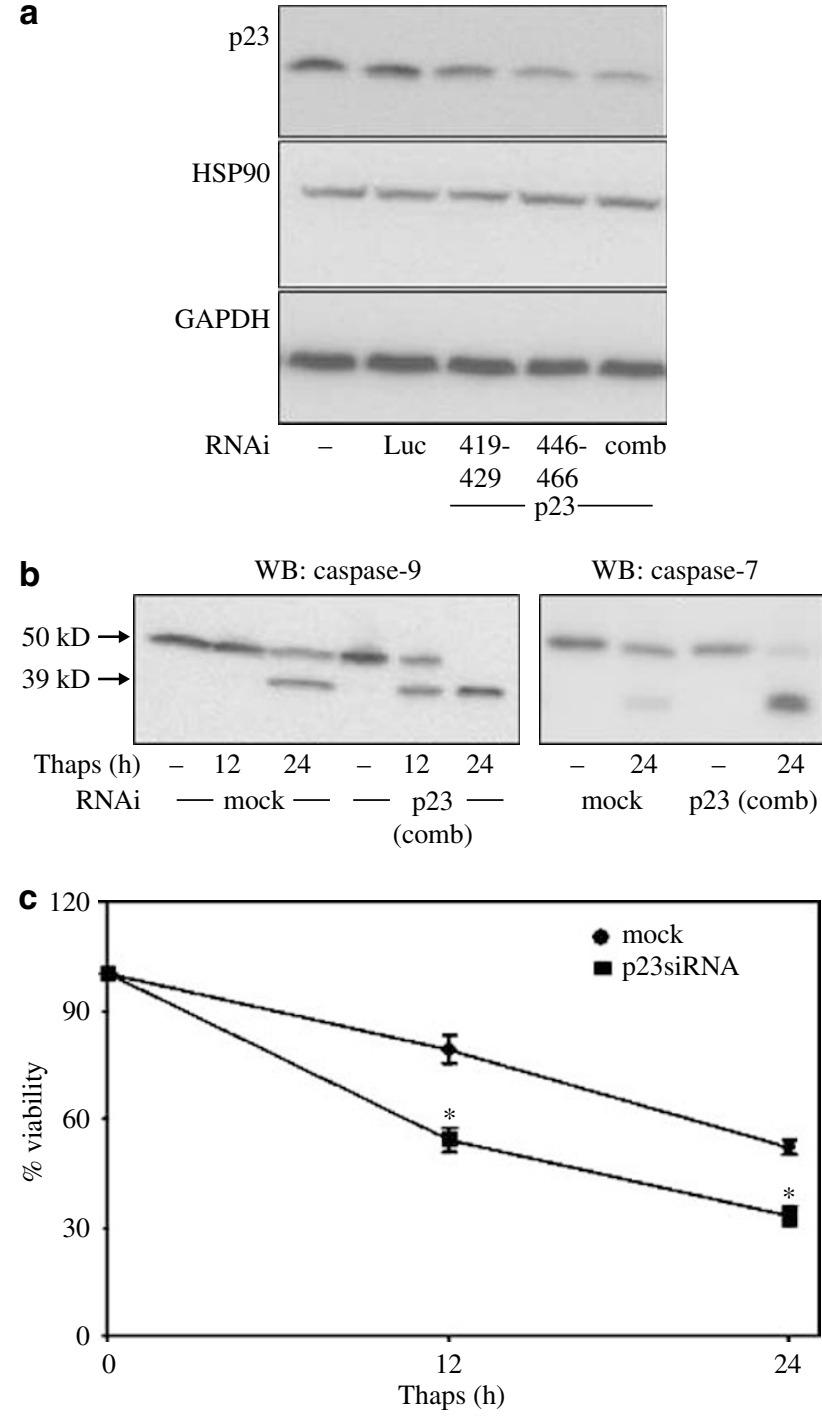

Figure 5 Transfection of siRNA-targeting p23. (a) Small interfering RNAs (siRNAs) were designed to target two regions each for p23. Apaf- $1^{-1-}$ cells were first transfected with $80 \mathrm{nM}$ siRNA as described in Materials and Methods. To estimate the efficiency of transfection, fluorescently labeled siRNA targeting the luciferase gene was used. Cells were gently lifted $36 \mathrm{~h}$ after siRNA transfection and washed once with PBS at room temperature. Cell lysates were immunoblotted with anti-p23 and anti-HSP90 antibodies. None of the siRNAs crossinhibited the expression of HSP90. Cell extracts were also probed with antiGAPDH as a loading control. (comb) indicates cotransfection of the two siRNAs designed to target the p23 gene transcript (nucleotides 419-429 and 446-466). (b) Effect of RNA interference on ER stress-induced caspase activation and cell death. Apaf- $1^{-1-}$ cells were first transfected with $80 \mathrm{nM}$ siRNA as described in Materials and Methods. A combination of both siRNAs (nucleotides 419-429 and 446-466) was transfected to optimize the decrease of expression of p23 (Figure $5 \mathrm{a}, \mathrm{comb}$ ). At $24 \mathrm{~h}$ after transfection, cells were exposed to $50 \mathrm{nM}$ thapsigargin (Thaps) for 12 and $24 \mathrm{~h}$. Cells were gently lifted and washed once with PBS at room temperature. Cell extracts were subjected to SDS-PAGE and Western blotting. Membranes were probed with anti-caspase- 9 or -7 antibody. (c) Thapsigargin-induced cell death was quantified by the Trypan blue procedure as described in Materials and Methods. ${ }^{\star} P<0.05$

thapsigargin after transfection with the p23 siRNAs. As shown in Figure 5b, inhibition of p23 expression by siRNA resulted in an enhancement of thapsigargin-induced caspase- 9 and -7 processing. Similarly, inhibition of $\mathrm{p} 23$ expression by siRNA 
significantly rendered cells more susceptible to pcd induced by thapsigargin (Figure $5 \mathrm{c}$ ). Similar results to those of thapsigargin were also obtained with brefeldin-A (data not shown). The results support the notion that p23 may play a protective role during ER stress; and either prolonged ER stress (resulting in p23 cleavage), or downregulation of p23 expression, renders cells more susceptible to pcd induced by ER stress.

\section{Interaction of p23, PUMA and Bax}

Recent studies have disclosed the roles of several ER stressinduced cell-death effectors, including members of the $\mathrm{Bcl}-2$ family, ${ }^{6}$ and p53-dependent gene products like PUMA/Bbc3 and scotin. ${ }^{6,14,15}$ All of these gene products have been shown to link ER stress to the mitochondrial apoptotic pathways.

To complement the functional studies of p23 in ER stressinduced apoptosis, we asked whether any of the above effector molecules associate with p23. We performed coimmunoprecipitation of endogenous proteins and repeated these studies following vector-driven expression of Flag-p23. We did not observe co-immunoprecipitation of p23 with Bik, Bak or scotin before or after ER stress (data not shown). However, endogenous p23, Flag-p23 and the caspase cleavage site mutant protein p23D142N co-immunoprecipitated with endogenous PUMA in untreated MCF-7 cells, providing evidence of interaction between p23 and PUMA (Figure $6 a$ and $b$ ). The interaction of p23 and PUMA was also evaluated in cells treated with thapsigargin and brefeldin- $A$ for different time periods. As shown in Figure 6b, while PUMA associated strongly with the caspase mutant protein p23D142N before and after ER stress, WTp23 interaction with PUMA decreased with time of treatment (Figure 6a). The interaction of these proteins was weak at $24 \mathrm{~h}$, and more so at $36 \mathrm{~h}$ of treatment. This is the time point at which WTp23 undergoes caspase-dependent cleavage (Figure 2).

In order to exclude the possibility that the decrease in p23PUMA co-immunoprecipitation was simply due to a decrease in PUMA expression during prolonged ER stress, we assessed the expression of PUMA in cell extracts isolated from untreated and ER stress-induced cells. As shown in Figure 6c, ER stress-induced induction of PUMA occurred independently of p53 regulation, and PUMA did not undergo degradation with prolonged ER stress. Thus, the most likely explanation for the weak interaction of PUMA and WTp23 during ER stress may be cleavage of p23 and a resultant failure to maintain PUMA binding. ${ }^{16}$ This may also explain the strong interaction of the uncleavable mutant protein p23D142N with PUMA, which was irrespective of ER stress.

Since earlier reports suggested that p23-associated HSP90 may define a subpopulation of HSP90 that is involved in protein binding, folding or processing of steroid receptors, ${ }^{9,17}$ we asked whether the association of p23 with PUMA is direct or is dependent on HSP90 binding. As shown in Figure 7a, while p23 associated with HSP90 before and after ER stress, there was no evidence of interaction between PUMA and HSP90 (Figure 7a). Similar results were obtained when we performed reciprocal immunoprecipitations (data not shown). The results suggest that, despite being considered a a
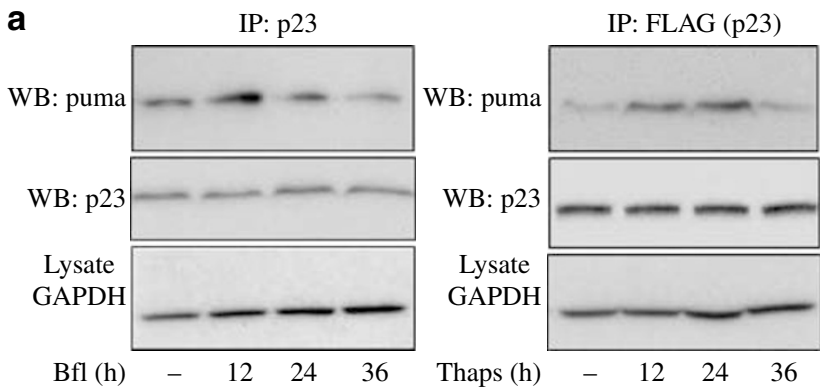

b
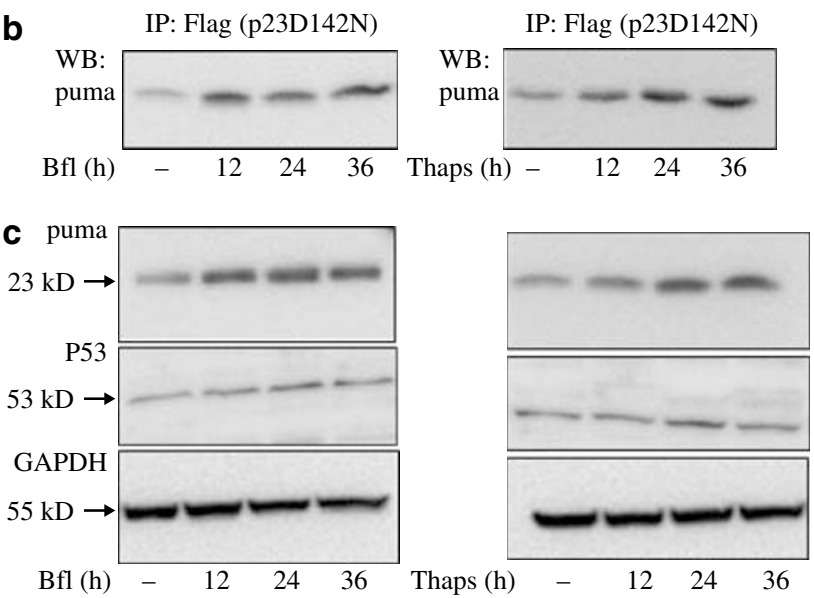

Figure 6 Co-immunoprecipitation of p23, and PUMA (a and b) Coimmunoprecipitation was carried out in untransfected MCF-7 cells and cells transfected with $6 \mu \mathrm{g}$ of WTp23FLAG cDNA (a) or FLAGp23D142N (b). Transfection was allowed to proceed for $24 \mathrm{~h}$ before the addition of ER stress inducers. ER stress was induced by the addition of $2.0 \mu \mathrm{M}$ brefeldin-A (Bfl) or $2.0 \mu \mathrm{M}$ thapsigargin (Thaps) for different time periods. Cells were gently lifted and washed once with PBS at room temperature. Immunoprecipitations were performed with anti-p23 antibody or anti-Flag monoclonal antibody (for Flagtagged p23), and the resulting immunoprecipitates were analyzed by immunoblotting using antisera specific for PUMA or p23. (c) Cellular extracts were prepared from MCF-7 cells treated with $2.0 \mu \mathrm{M}$ brefeldin-A (Bfl) or $2.0 \mu \mathrm{M}$ thapsigargin (Thaps) for different time periods. Cells were gently lifted washed once with PBS at room temperature. Cell extracts were subjected to SDS-PAGE and Western blotting. Membranes were probed with anti-PUMA antibody, antiP53 antibody and anti-GAPDH antibody

cochaperone protein of HSP90, there exists a pool of p23 that interacts with PUMA to the exclusion of HSP90, arguing for additional functions of p23 that are independent of HSP90. ${ }^{17}$ The results underscore the importance of a p23PUMA interaction that is independent of HSP9O binding, and the subsequent release of PUMA from the p23-PUMA complex in association with the triggering of the cell death process. Since p23D142N blocked both caspase cleavage and release of PUMA and inhibits apoptosis, the release of PUMA from the p23-PUMA complex may be an important event in ER stress-induced apoptosis. Furthermore, PUMA-/cells are resistant to ER-stress induced cell death based on an earlier report. ${ }^{15}$ The extent of protection seen in PUMA KO cells following ER stress is less than that afforded by uncleavable p23. ${ }^{15}$

PUMA induces a conformational modification of Bax, resulting in its accumulation on the mitochondria and triggering the release of cytochrome $c$ to activate the final 
a
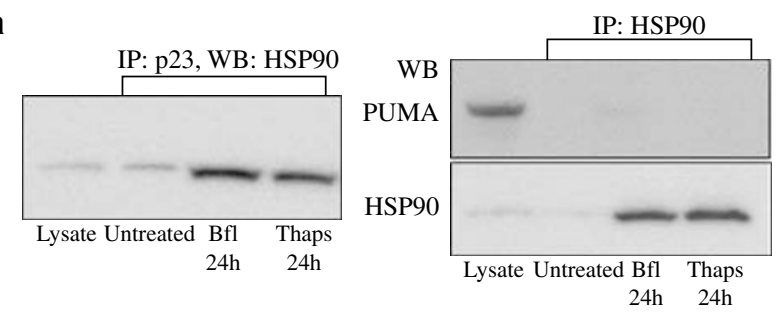

b
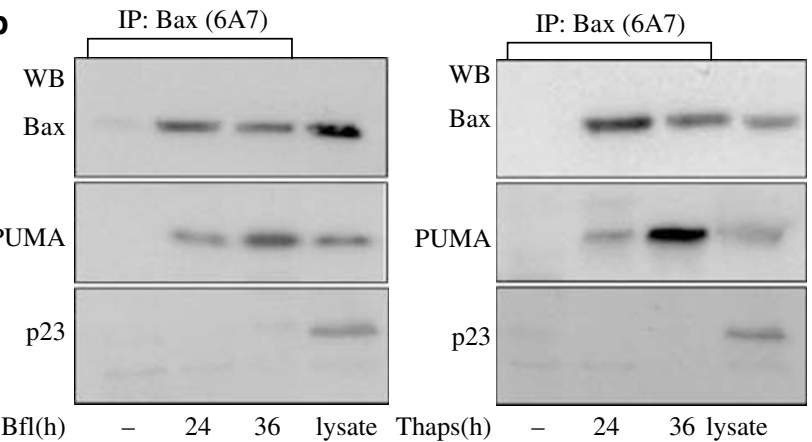

Figure 7 Co-immunoprecipitation of p23, HSP90, PUMA and Bax. (a) Coimmunoprecipitation was carried out in untransfected MCF-7 cells. ER stress was induced by the addition of $2.0 \mu \mathrm{M}$ brefeldin-A (Bfl) or $2.0 \mu \mathrm{M}$ thapsigargin (Thaps) for $24 \mathrm{~h}$. Cells were gently lifted and washed once with PBS at room temperature. Immunoprecipitations were performed with anti-p23 antibody or anti-HSP9O antibody and the resulting immunoprecipitates were analyzed by immunoblotting using antisera specific for HSP90 or PUMA. (b) Co-immunoprecipitation was carried out in untransfected MCF-7 cells. ER stress was induced by the addition of $2.0 \mu \mathrm{M}$ brefeldin-A (Bfl) or $2.0 \mu \mathrm{M}$ thapsigargin (Thaps) for $24 \mathrm{~h}$. Cells were gently lifted washed once with PBS at room temperature. Immunoprecipitations were performed with anti-Bax6A7 antibody that recognizes conformationally changed Bax, and the resulting immunoprecipitates were analyzed by immunoblotting using antisera specific for Bax (anti-Bax N20), PUMA and p23 antibody

steps of pcd. ${ }^{15,18}$ BH3-only proteins like PUMA and Bid have been shown to interact with the first helix of Bax, induce a change in its conformation and stimulate its mitochondrial activity leading to apoptotic cell death. ${ }^{19}$ ER stress inducers also trigger the Bax conformational change and mitochondrial translocation, leading to the release of Smac and Omi and activation of pcd. ${ }^{20,21}$ In order to define further the functional implication of the p23-PUMA interaction, we examined the ability of p23 and PUMA to associate with Bax before and after ER stress. Immunoprecipitation was performed with the anti-Bax6A7 antibody which recognizes conformationally altered Bax. ${ }^{19,22}$ We did not observe co-immunoprecipitation of p23 with Bax either before or after ER stress (Figure 7b). While there was no evidence of interaction between Bax and PUMA in untreated MCF-7 cells (Figure 7b), PUMA associated strongly with Bax only following ER stress. The interaction of these two proteins was evident at 24 and $36 \mathrm{~h}$ of treatment. These are also the time points corresponding to caspase-dependent cleavage of p23 and dissociation of PUMA from the p23PUMA complex. The results indicate that prolonged ER stress triggers caspase-dependent cleavage of p23 followed by disruption of the PUMA-p23 complex and subsequent association of PUMA and Bax to trigger mitochondrialdependent pcd.

\section{Discussion}

The ER is extremely sensitive to changes that affect its structure, integrity and function. ${ }^{2,3}$ Changes in calcium homeostasis, inhibitors of protein glycosylation, viral infections, hypoxia, ischemia, and growth factor depletion can all disrupt protein synthesis and folding, resulting in unfolded or misfolded proteins. Accumulation of unfolded $/ \mathrm{misfolded}$ proteins creates an imbalance between the synthesis of new proteins and the ER's ability to process newly synthesized proteins, resulting in 'ER stress'.1,2 Prolonged ER stress overwhelms cellular protective mechanisms, ultimately triggering cell death. ER stress-induced cell death is coupled to specific independent death pathways, as well as demonstrating crosstalk with the intrinsic and extrinsic apoptotic pathways. $7,8,12,23,24$

We and others have identified several ER stress-induced cell death modulators that include members of the $\mathrm{Bcl}-2$ family, p53-dependent gene products and caspases. ${ }^{4-7}$ Although we identified HSP90 by two-dimensional gel electrophoresis coupled with MALDI-TOF mass spectrometry and nano-LC-ESI-MS/MS, its cochaperone protein p23 displayed a more consistent profile in ER stress-induced cell death. Therefore, the present studies were undertaken to define the role of this small chaperone protein. p23 is a highly conserved and widely expressed chaperone protein involved in the assembly of protein complexes, such as steroid hormone receptor and telomerase complexes. ${ }^{9,25,26}$ The chaperone activity of p23 prevents aggregation of denatured proteins. p23 is also highly expressed in mammary carcinomas. $^{27}$

We report here that p23 is cleaved to yield a $19 \mathrm{kD}$ product during ER stress-induced cell death triggered by various agents including tunicamycin, brefeldin- $A$ and thapsigargin. Primary neuronal cells subjected to hypoxia were also susceptible to ER stress and p23 cleavage. p23 was processed by caspases- 7 and -3 but not caspase- 8 . A recent report also indicated that p23 undergoes a caspase-dependent cleavage in chemotherapy-induced apoptosis, ${ }^{27}$ suggesting that cleavage of p23 may be an indication of cells undergoing some form of stress. To our knowledge, p23 is the first chaperone protein to be identified as a caspase substrate.

Despite generating several single, double and triple caspase mutant sites, caspase-3- and caspase-7-dependent cleavage of p23 was prevented only by the D142N mutation. Our results are at odds with the report by Gausdal et al., ${ }^{27}$ who demonstrated that p23 is cleaved at D142 and D145. While these authors used an in vitro reticulocyte lysate ${ }^{35} \mathrm{~S}-\mathrm{p} 23$ cleavage assay, we incubated recombinant purified caspases with extracts isolated from cells transfected with the p23 mutants. The most plausible explanation for this discrepancy is that, in the cellular extracts, p23 may be bound to other proteins (or be phosphorylated or otherwise modified), and therefore expose only the D142 site for cleavage, as opposed to ${ }^{35} \mathrm{~S}-\mathrm{p} 23$ in the reticulocyte lysate that may have more than one site accessible to caspase proteolysis. Mutation of the p23D142N site not only blocked the cleavage by caspases and formation of the $19 \mathrm{kD}$ product, but also attenuated the cell-death process, suggesting that ER stress-induced cell 
death may proceed through caspase-7- and casapse-3mediated cleavage of $\mathrm{p} 23$.

Using complementary approaches, including immunodepletion and downregulation of the expression of p23 by RNAi, resulted in enhanced ER stress-induced apoptosis, suggesting a role for p23 as an antiapoptotic protein. While the increase in apoptosis seen after downregulating $\mathrm{p} 23$ by siRNA is significant but in and of itself not very impressive, this is just one piece of data that, taken with the transfection studies, effects of uncleavable p23, and interaction studies, supports the conclusion that p23 and its cleavage represent mediators of ER stress-induced apoptosis. It has been observed that the entire carboxy-terminus of p23 is required for its chaperone activity and to enhance the assembly of protein complexes. ${ }^{16,17}$ Removal of the C-terminal 30 amino acids abolishes its chaperone activity. ${ }^{16}$ Similarly, it is possible that ER stress-induced cleavage of p23 at the D142 site, resulting in the $19 \mathrm{kD}$ product, abolishes the ability of p23 to act as an antiapoptotic protein, thus rendering cells more susceptible to pcd. It is also possible that the $19 \mathrm{kD}$ cleaved product may display proapoptotic activity analogous to proteins such as $\mathrm{Bcl}-2$ and Bid. ${ }^{28,29}$

PUMA/Bbc3 is a $\mathrm{BH} 3-$ only proapoptotic gene that is significantly upregulated after prolonged ER stress triggered by tunicamycin and thapsigargin. ${ }^{15}$ Induction of Bbc3/PUMA is also observed in primary neuron cultures and in response to cerebral ischemia in vivo, demonstrating the involvement of PUMA in ER stress-induced cell death. ${ }^{15,30}$ While PUMA was previously identified as a p53 target gene, ${ }^{31-33}$ induction of PUMA has also been shown to involve p53-independent regulation. ${ }^{15,30,31}$ PUMA links the ER stress response to the mitochondrial apoptosis pathway independently of p53 expression. ${ }^{15,30}$

Our results are compatible with a p53-independent increased expression of PUMA in brefeldin- and thapsigargintreated cells. Our studies demonstrating the interaction of an HSP90-independent subpopulation of p23 with PUMA provide a potential mechanism by which p23 may regulate ER stressinduced cell death. Prolonged ER stress triggers caspasemediated cleavage of p23 that in turn abolishes the interaction of p23 and PUMA. This release of PUMA from p23 may increase the PUMA available for interaction with Bax and the triggering of apoptosis. Our results demonstrating the interaction of Bax and PUMA are in agreement with recent work by Cartron et al. ${ }^{19}$ showing the interaction of Bax, Bid and PUMA, allowing Bid and PUMA to function as death agonists of Bax. These studies have reported that PUMA binds to the first helix of Bax and triggers a conformational modification of Bax, resulting in its accumulation on the mitochondria and inducing the release of cytochrome $c$ to activate the final steps of pcd. ${ }^{15,18,19}$ These reports argue that the current 'dogma,' that is, that BH3-only proteins such as PUMA act as antagonists of antiapoptotic Bcl-2 family members such as Bcl-xL ${ }^{34,35}$ but not as direct interactors with Bax or Bak, may turn out to be an overly simplistic model, and that, instead, at least some of these proteins may interact with Bax (or with both Bax and Bcl2). Similarly, Reimertz et al. ${ }^{15}$ recently demonstrated colocalization of Bax and PUMA in SH-SY5Y cells during activation of the mitochondrial apoptotic pathway triggered by tunicamycin.
It is interesting to note that, despite being a cochaperone of HSP90, p23 binds to PUMA independently of HSP90. It has been postulated that p23 may exhibit chaperone activity in the absence of HSP90. ${ }^{17,26,36}$ This suggests that there may be several pools of p23, one of which is closely associated with HSP90 and involved in binding misfolded proteins ${ }^{37}$ and a second pool of p23 that binds specifically to PUMA (and possibly other molecules). Interestingly, while prolonged ER stress abolishes the interaction of p23 and PUMA, it does not affect the p23-HSP90 interaction (Figure 6d). Earlier results demonstrated that removal of the C-terminal tail of p23 disrupts the chaperone activity of p23 but does not affect heterocomplex formation with HSP90. ${ }^{10,16,17}$

Earlier reports demonstrated that activation of apoptosis by ER stress features an Apaf-1 and cytochrome $c$-independent pathway. ${ }^{12,38}$ It is possible that prolonged ER stress may simultaneously trigger more than one cell-death pathway, some of which feature molecules that link to the mitochondria and others that activate pathways that trigger caspase activation independent of mitochondria. In summary, the present work suggests that the activation of apoptosis by ER stress features p23, a small chaperone protein. In addition to its chaperone function, p23 may also function independently of HSP90 as an antiapoptotic protein. Further work will be required to determine whether p23 plays additional roles in ER stress-induced cell death. Studies are also ongoing to determine whether PUMA functions with or without the p23cleaved product in eliciting ER stress-induced cell death.

\section{Materials and Methods}

\section{Cells, culture conditions, plasmids and transfection}

Apaf- $1^{-1-}$ immortalized mouse embryonic fibroblasts, human embryonic kidney $293 \mathrm{~T}$ cells and MCF-7 breast cancer cells were cultured in DMEM containing $10 \%$ FBS and $1 \%$ penicillin/streptomycin. Apaf- $1^{-1-}$ fibroblasts were derived by retroviral-driven T-antigen expression in Apaf-1 null mouse embryonic fibroblasts and were provided by Dr. Peter Gruss, Max Planck Institute for Biophysical Chemistry, Göttingen, Germany. These fibroblasts are relatively resistant to cell death initiated by specific proapoptotic agents that utilize the intrinsic (mitochondrial dependent) pathway (directly or indirectly), including Fas (in type II cells) and ceramide-mediated pathways. ${ }^{7,12}$ However, the exposure of these Apaf-1null cells to ER stress-inducing agents has been shown to result in a timedependent decrease in cell viability. ${ }^{12}$ MCF-7 breast cancer cells are

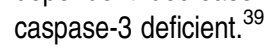

Cortical neuron cultures were prepared from 16-day Charles River CD1 mouse embryos. Experiments were carried out at an AAALAC-accredited site, performed in accordance with the National Institutes of Health Guide for the Care and Use of Laboratory Animals, approved by local committee (IACUC) review, and every effort was made to minimize animal suffering and reduce the number of animals used. Cerebral hemispheres were removed aseptically, freed of meninges, olfactory bulbs, basal ganglia and hippocampi, and incubated at $37^{\circ} \mathrm{C}$ in $\mathrm{Ca}^{2+}$ - and $\mathrm{Mg}^{2+}$-free Earle's balanced salt solution containing $0.25 \%$ trypsin for $2 \mathrm{~min}$. Then, $10 \%$ horse serum and $10 \%$ fetal bovine serum were added and cells were suspended by trituration. After allowing undispersed tissue to settle for $3 \mathrm{~min}$, the supernatant was transferred to a $15-\mathrm{ml}$ centrifuge tube and centrifuged for $1 \mathrm{~min}$ at $200 \times \mathrm{g}$. Cells were resuspended in Neurobasal medium 
containing 2\% B27 supplement, $2 \mathrm{~mm}$ glutamine, $20 \mathrm{ng} / \mathrm{ml}$ fibroblast growth factor, $1 \%$ penicillin and streptomycin (Life Technology, Rockville, MD, USA). Cell suspensions were filtered through a $70-\mu \mathrm{m}$ Falcon nylon cell strainer and seeded at $3 \times 10^{5}$ cells per well on 24-well Corning culture dishes coated with $100 \mu \mathrm{g} / \mathrm{ml}$ of poly-D-lysine. Cultures were incubated at $37^{\circ} \mathrm{C}$ in humidified $95 \%$ air $/ 5 \% \mathrm{CO}_{2}$ for 4 days, and then onehalf of the medium was replaced with Neurobasal medium containing $2 \%$ B27. Experiments were conducted at 8 days in vitro, when $>99 \%$ of cells were neurons, as determined by immunoreactivity for the microtubuleassociated protein MAP2 but not glial fibrillary acidic protein.

Human p23 cDNA was generously provided by Dr. David Toft (Mayo Clinic, Rochester, MN, USA). N-terminal Flag-p23 was subcloned into a pcDNA3 expression vector (Invitrogen) by PCR-amplification of p23. Using the QuikChange Site-Directed Mutagenesis Kit (Stratagene, La Jolla, CA, USA), the following potential caspase cleavage site mutants were generated: D142N, D145N, D150N, D153N, D150/153N and D145/150/ $153 \mathrm{~N}$. The sequences of all constructs were confirmed by DNA sequencing, and Western blot analyses were performed to verify protein expression. Transient transfections of MCF-7 cells with Superfect (Qiagen) or 293T cells with Lipofectamine 2000 (Invitrogen) were performed as described earlier ${ }^{8,12}$ and according to the manufacturer's instructions. Typically, $2 \times 10^{6}$ cells were seeded into $10 \mathrm{~cm}$ dishes, respectively, and transfected a day later with $6 \mu \mathrm{g}$ of the specified construct using a ratio of $1 \mu \mathrm{g}$ DNA: $5 \mu$ l of transfection reagent. The transfection efficiency using these conditions was approximately $65-70 \%$.

\section{Hypoxia}

To induce hypoxia, cultures were placed in modular incubator chambers (Billups-Rothenberg, Del Mar, CA, USA) for $0-24 \mathrm{~h}$ at $37^{\circ} \mathrm{C}$, in humidified $95 \%$ air $/ 5 \% \quad \mathrm{CO}_{2}$ (control) or humidified $95 \% \mathrm{~N}_{2} / 5 \% \quad \mathrm{CO}_{2}$ (hypoxia). Cultures were then returned to normoxic conditions for the remainder (if any) of $24 \mathrm{~h}$.

\section{Cell-free extracts, cell fractionation and Western blotting}

Cell-free cytoplasmic extracts and microsomes were prepared as previously described. ${ }^{8,12}$ The $20000 \times g(14000 \mathrm{rpm}$, Eppendorf Centrifuge, $5417 \mathrm{R}$ ) supernatant that lacks whole cells, nuclei and mitochondria was recentrifuged at $400000 \times g(100000 \mathrm{rpm}$ Beckman Coulter Optima TLX Ultracentrifuge) for $1 \mathrm{~h}$ for the preparation of microsomes. The resulting supernatant contains the soluble cytosolic fraction (S) and the microsomal pellet $(P)$ represents ER membrane and lumen proteins, as well as Golgi membranes. Cellular fractions were probed with anti-PDI (protein disulfide isomerase) antibody or anti-GRP78 antibody and anti- $\beta$ tubulin as standard marker proteins for ER and cytosol, respectively. SDSPAGE and Western blot analyses were performed as described earlier. ${ }^{7,8,12,24}$ Membranes were probed with a 1:500 dilution of a mouse-specific anticaspase-9 polyclonal antibody (Cell Signaling Laboratories), a 1:500 dilution of anti-PDI monoclonal antibody, a 1:500 dilution of anti- $\beta$-tubulin monoclonal antibody, a 1:1000 dilution of anti-p23 monoclonal antibody (all from BD Biosciences), a 1: 1000 dilution of antiFLAG monoclonal antibody, 1:500 dilution of anti-PUMA polyclonal antibody, 1:500 dilution of anti-Bax (6A7) monoclonal antibody (all from Sigma), 1:500 dilution of anti-PUMA polyclonal antibody from (Calbiochem PC686), 1:500 dilution of anti-Bax (N-20) antibody (Santa Cruz Biotechnology), 1:500 dilution of anti-GRP78 polyclonal antibody, a 1:500 dilution of anti-Hsp90 monoclonal antibody (all from Stressgen
Bioreagents), and a 1:50000 dilution of anti-GAPDH rabbit polyclonal antibody (Research Diagnostics Inc.). The pan-caspase inhibitor (ZVADfmk) was obtained from Calbiochem and dissolved in dimethyl formamide as a $10 \mathrm{mM}$ stock solution.

\section{Immunofluorescence staining}

Cortical neuronal cells grown on poly-D-lysine-coated culture slides (Becton Dickinson Labware, Bedford, MA, USA) were washed with phosphate-buffered saline and fixed with $4 \%$ paraformaldehyde in phosphate-buffered saline for $20 \mathrm{~min}$. For the detection of p23, cells were stained with anti-p23 monoclonal antibody (1 : 100 dilution, BD Transduction labs) as primary antibody and 488-conjugated donkey anti-mouse IgG ( $1: 250$ dilution, Molecular Probes) as the secondary antibody. Cells were also stained with anti-calreticulin polyclonal antibody (1:250 dilution, Stressgen) and 555-conjugated donkey anti-rabbit IgG (1:500 dilution, Molecular Probes) as the secondary antibody. Stained cells were examined using a Nikon PCM 2000 confocal mounted on Eclipse-E800 microscope equipped with appropriate filters. Z-stacks of the cells were acquired with voxel size of $0.048 \times 0.048 \times 0.25 \mu \mathrm{m}^{3}$ using PCl-Imaging software. In Bitplane Imaris 4.1.3 Suite, individual cells were cropped out of stacks. Subsequently, each cell's data set was run through Huygens deconvolution software applying Classic MLE and using constant parameters for like primary/secondary combinations. Colocalization statistics were generated in Imaris with each ROI set for the calretriculin (ER) channel and employing automatic threshholding.

\section{D gel electrophoresis protocol for the identification of microsomal proteins}

Two-dimensional gel electrophoresis and analysis of the bioinformatics database system were performed as described earlier. ${ }^{7}$

\section{Immunoprecipitations and immunodepletions}

Transient transfection, cell lysis and immunoprecipitation were performed as previously described. ${ }^{7,8,24}$ To understand protein-protein interaction, we performed co-immunoprecipitation of endogenous proteins and in some instances repeated these studies following vector-driven expression of Flag-p23. Immunoprecipitation of conformationally changed Bax with the anti-Bax $6 \mathrm{~A} 7$ antibody was as described. ${ }^{22}$ For immunodepletion and caspase-processing assays, microsomes were isolated from cell extracts prepared from thapsigargin/brefeldin-A-treated cells as previously described. ${ }^{7,12}$ The microsomal pellet was washed twice with $10 \mathrm{mM}$ Tris-Cl/ $\mathrm{NaCl} \mathrm{pH} \mathrm{7.4,} \mathrm{reconstituted} \mathrm{in} \mathrm{the} \mathrm{same} \mathrm{buffer} \mathrm{and} \mathrm{briefly} \mathrm{sonicated}$ to disperse the pellet fraction. A total of $200 \mu \mathrm{g}$ protein from the cell extract or the microsomal pellet was subjected to immunodepletion using mouse anti-p23 antibody. Following an overnight incubation at $4{ }^{\circ} \mathrm{C}$ with the antibodies, protein A/G-Sepharose was added to the samples and incubated at $4^{\circ} \mathrm{C}$ for an additional $6 \mathrm{~h}$. Samples were spun briefly to pellet the protein A/G-Sepharose conjugate. The supernatant was subjected to SDS-PAGE and probed for (a) p23 protein that would indicate the extent of immunodepletion, and (b) probed for PDI as an ER marker protein.

\section{Caspase-processing assay}

Caspase-processing assays were carried out according to the manufacturer's instructions by incubating $50-100 \mu \mathrm{g}$ of the supernatant protein with purified active caspase-3 $(50 \mathrm{ng} / \mathrm{ml})$, caspase- $7(100 \mathrm{ng} / \mathrm{ml})$ or 
$\left(1.0 \mu \mathrm{g} / \mathrm{ml}\right.$ ) caspase-8 (all from BD Pharmingen) at $37^{\circ} \mathrm{C}$ for $1 \mathrm{~h}$. Following the reactions, samples were analyzed by SDS-PAGE and Western blotting. Membranes were probed with anti-p23 antibody or anti-FLAG antibody for detection of p23 protein.

\section{siRNA synthesis and transfection}

siRNA were generated by in vitro transcription using the Silencer siRNA Construction Kit from Ambion as described earlier. ${ }^{7}$ siRNAs were designed to target two or more regions for p23 based on predicted accessible (loop) and unique (specific) regions. The following siRNA sequences were designed to specifically target the mouse p23 gene: p23 (GenBank: AF153479) regions 419-439 (5' AAGTAGATGGAGCAGAT GATG) and 446-466 (5'AAGACAGTGATGATGAAAAGA). Apaf-1 ${ }^{-1-}$ cells $\left(2.5 \times 10^{5}\right.$ cells $/ 10 \mathrm{~cm}$ dish) were grown in DMEM (Life Technologies) supplemented with $10 \%$ fetal bovine serum (Sigma) with no antibiotics for $16 \mathrm{~h}$. Transfection of siRNA specific for each target was carried out as described earlier ${ }^{7}$ using Ambion's siPORT Amine transfection reagent according to the manufacturer's instructions. To estimate the efficiency of the transfections, fluorescently labeled siRNAs targeting the luciferase gene (region 152-173) from the luciferaseexpressing vector pGL2-control (Promega) was also used. At $36 \mathrm{~h}$ after p23 siRNA transfection, cell extracts were prepared and subjected to SDSPAGE and Western blot analysis.

In order to study the effect of ER stress on cells after reducing the p23 concentration, cells were transfected with p23 siRNA. At $24 \mathrm{~h}$ after transfection, cells were exposed to $50 \mathrm{nM}$ thapsigargin (Thaps) for 12 or $24 \mathrm{~h}$. Thapsigargin-induced cell death was quantified and cell extracts were also analyzed by SDS-PAGE and Western blot for caspase- 9 processing.

\section{Evaluation of apoptosis}

Assessment of cell death was carried out by pelleting floating and adherent cells (after trypsinization) as previously described. ${ }^{7,12}$ The pellet was resuspended in $1 \times \mathrm{PBS} / 0.4 \%$ Trypan blue and cells were counted using a hemocytometer. Cell death was determined as the percentage of dead cells over the total number of cells. Statistical significance was determined by two-way analysis of variance (ANOVA) analysis. Differences were considered statistically significant for $P<0.05$.

\section{Acknowledgements}

We thank members of the Bredesen laboratory for helpful comments and discussions, Drs. Birgit Schilling and Bradford W Gibson for Mass Spectrometry analysis, Dr. Gabriel del Rio for analysis of the protein structure, Dr. David Toft for critical review of the manuscript and Molly Susag for administrative assistance. This work was supported by Grants from the National Institutes of Health (NS33376 to DEB and RVR, AG12282 and NS45093 to DEB).

\section{References}

1. Rutkowski DT and Kaufman RJ (2004) A trip to the ER: coping with stress. Trends Cell Biol. 14: 20-28

2. Ron D (2002) Translational control in the endoplasmic reticulum stress response. J. Clin. Invest. 110: 1383-1388
3. Kaufman RJ (1999) Stress signaling from the lumen of the endoplasmic reticulum: coordination of gene transcriptional and translational controls. Genes Dev. 13: 1211-1233

4. Rao RV, Ellerby HM and Bredesen DE (2004) Coupling endoplasmic reticulum stress to the cell death program. Cell Death Differ. 11: 372-380

5. Rao RV and Bredesen DE (2004) Misfolded proteins, endoplasmic reticulum stress and neurodegeneration. Curr. Opin. Cell Biol. 16: 653-662

6. Ward MW, Kogel D and Prehn JH (2004) Neuronal apoptosis: BH3-only proteins the real killers? J. Bioenerg. Biomembr. 36: 295-298

7. Rao RV, Poksay KS, Castro-Obregon S, Schilling B, Row RH, Del Rio G, Gibson BW, Ellerby HM and Bredesen DE (2004) Molecular components of a cell death pathway activated by endoplasmic reticulum stress. J. Biol. Chem. 279: $177-187$

8. Rao RV, Hermel E, Castro-Obregon S, del Rio G, Ellerby LM, Ellerby HM and Bredesen DE (2001) Coupling endoplasmic reticulum stress to the cell death program. Mechanism of caspase activation. J. Biol. Chem. 276: 33869-33874

9. Felts SJ and Toft DO (2003) p23, a simple protein with complex activities. Cell Stress Chaperones 8: 108-113

10. Weaver AJ, Sullivan WP, Felts SJ, Owen BA and Toft DO (2000) Crystal structure and activity of human p23, a heat shock protein 90 co-chaperone. J. Biol. Chem. 275: 23045-23052

11. Gazit G, Lu J and Lee AS (1999) De-regulation of GRP stress protein expression in human breast cancer cell lines. Breast Cancer Res. Treat 54: 135-146

12. Rao RV, Castro-Obregon S, Frankowski H, Schuler M, Stoka V, Del Rio G, Bredesen DE and Ellerby HM (2002) Coupling Endoplasmic Reticulum Stress to the Cell Death Program. AN Apaf-1-independent intrinsic pathway. J. Biol. Chem. 277: 21836-21842

13. Boyce M, Bryant KF, Jousse C, Long K, Harding HP, Scheuner D, Kaufman RJ, Ma D, Coen DM, Ron D and Yuan J (2005) A selective inhibitor of elF2alpha dephosphorylation protects cells from ER stress. Science 307: 935-939

14. Bourdon JC, Renzing J, Robertson PL, Fernandes KN and Lane DP (2002) Scotin, a novel p53-inducible proapoptotic protein located in the ER and the nuclear membrane. J. Cell Biol. 158: 235-246

15. Reimertz C, Kogel D, Rami A, Chittenden T and Prehn JH (2003) Gene expression during ER stress-induced apoptosis in neurons: induction of the BH3-only protein Bbc3/PUMA and activation of the mitochondrial apoptosis pathway. J. Cell Biol. 162: 587-597

16. Weikl T, Abelmann K and Buchner J (1999) An unstructured C-terminal region of the Hsp90 co-chaperone p23 is important for its chaperone function. J. Mol. Biol. 293: 685-691

17. Oxelmark E, Knoblauch R, Arnal S, Su LF, Schapira M and Garabedian MJ (2003) Genetic dissection of p23, an Hsp90 cochaperone, reveals a distinct surface involved in estrogen receptor signaling. J. Biol. Chem. 278: 36547-36555

18. Liu FT, Newland $A C$ and Jia $L$ (2003) Bax conformational change is a crucial step for PUMA-mediated apoptosis in human leukemia. Biochem. Biophys. Res. Commun. 310: 956-962

19. Cartron PF, Gallenne T, Bougras G, Gautier F, Manero F, Vusio P, Meflah K, Vallette FM and Juin $\mathrm{P}$ (2004) The first alpha helix of Bax plays a necessary role in its ligand-induced activation by the BH3-only proteins Bid and PUMA. Mol. Cell. 16: 807-818

20. Wei MC, Zong WX, Cheng EH, Lindsten T, Panoutsakopoulou V, Ross AJ, Roth KA, MacGregor GR, Thompson CB and Korsmeyer SJ (2001) Proapoptotic $B A X$ and $B A K$ : a requisite gateway to mitochondrial dysfunction and death. Science 292: 727-730

21. Chae HJ, Kim HR, Xu C, Bailly-Maitre B, Krajewska M, Krajewski S, Banares S, Cui J, Digicaylioglu M, Ke N, Kitada S, Monosov E, Thomas M, Kress CL, Babendure JR, Tsien RY, Lipton SA and Reed JC (2004) Bl-1 regulates an apoptosis pathway linked to endoplasmic reticulum stress. Mol. Cell 15: 355-366

22. Yamaguchi $\mathrm{H}$ and Wang $\mathrm{HG}$ (2004) $\mathrm{CHOP}$ is involved in endoplasmic reticulum stress-induced apoptosis by enhancing DR5 expression in human carcinoma cells. J. Biol. Chem. 279: 45495-45502

23. Nakagawa $T$ and Yuan J (2000) Cross-talk between two cysteine protease families. Activation of caspase-12 by calpain in apoptosis. J. Cell Biol. 150: 887-894

24. Rao RV, Peel A, Logvinova A, del Rio G, Hermel E, Yokota T, Goldsmith PC, Ellerby LM, Ellerby HM and Bredesen DE (2002) Coupling endoplasmic reticulum stress to the cell death program: role of the ER chaperone GRP78. FEBS Lett. 514: 122-128 
25. Zhu S and Tytgat $\mathrm{J}$ (2004) Evolutionary epitopes of Hsp90 and p23: implications for their interaction. FASEB. J. 18: 940-947

26. Bose S, Weikl T, Bugl H and Buchner J (1996) Chaperone function of Hsp90associated proteins. Science 274: 1715-1717

27. Gausdal G, Gjertsen BT, Fladmark KE, Demol H, Vandekerckhove J and Doskeland SO (2004) Caspase-dependent, geldanamycin-enhanced cleavage of co-chaperone p23 in leukemic apoptosis. Leukemia 18: 1989-1996

28. Cheng EH, Kirsch DG, Clem RJ, Ravi R, Kastan MB, Bedi A, Ueno K and Hardwick JM (1997) Conversion of Bcl-2 to a Bax-like death effector by caspases. Science 278: 1966-1968

29. Li H, Zhu H, Xu CJ and Yuan J (1998) Cleavage of BID by caspase 8 mediates the mitochondrial damage in the Fas pathway of apoptosis. Cell 94: 491-501

30. Jeffers JR, Parganas E, Lee Y, Yang C, Wang J, Brennan J, MacLean KH, Han J, Chittenden T, Ihle JN, McKinnon PJ, Cleveland JL and Zambetti GP (2003) Puma is an essential mediator of p53-dependent and -independent apoptotic pathways. Cancer Cell 4: 321-328

31. Han J, Flemington C, Houghton AB, Gu Z, Zambetti GP, Lutz RJ, Zhu L and Chittenden $T$ (2001) Expression of bbc3, a pro-apoptotic BH3-only gene, is regulated by diverse cell death and survival signals. Proc. Natl. Acad. Sci. USA 98: 11318-11323

32. Nakano K and Vousden KH (2001) PUMA, a novel proapoptotic gene, is induced by p53. Mol. Cell 7: 683-694
33. Yu J, Wang Z, Kinzler KW, Vogelstein B and Zhang L (2003) PUMA mediates the apoptotic response to $p 53$ in colorectal cancer cells. Proc. Natl. Acad. Sci. USA 100: 1931-1936

34. Danial NN and Korsmeyer SJ (2004) Cell death: critical control points. Cell 116: 205-219

35. Chen L, Willis SN, Wei A, Smith BJ, Fletcher JI, Hinds MG, Colman PM, Day CL, Adams JM and Huang DC (2005) Differential targeting of prosurvival Bcl-2 proteins by their $\mathrm{BH} 3-$ only ligands allows complementary apoptotic function. Mol. Cell 17: 393-403

36. Freeman BC, Toft DO and Morimoto RI (1996) Molecular chaperone machines: chaperone activities of the cyclophilin Cyp-40 and the steroid aporeceptorassociated protein p23. Science 274: 1718-1720

37. Garcia-Ranea JA, Mirey G, Camonis J and Valencia A (2002) p23 and HSP20/ alpha-crystallin proteins define a conserved sequence domain present in other eukaryotic protein families. FEBS Lett. 529: 162-167

38. Morishima N, Nakanishi K, Takenouchi H, Shibata T and Yasuhiko Y (2002) An endoplasmic reticulum stress-specific caspase cascade in apoptosis. Cytochrome c-independent activation of caspase-9 by caspase-12. J. Biol. Chem. 277: 34287-34294

39. Buckley CD, Pilling D, Henriquez NV, Parsonage G, Threlfall K, ScheelToellner D, Simmons DL, Akbar AN, Lord JM and Salmon M (1999) RGD peptides induce apoptosis by direct caspase-3 activation. Nature 397: 534-539 